Research Article

\title{
Application of BIM and 3D Laser Scanning for Quantity Management in Construction Projects
}

\author{
Thu Anh Nguyen, ${ }^{1,2}$ Phong Thanh Nguyen $\mathbb{D}^{3}{ }^{3}$ and Sy Tien Do ${ }^{1,2}$ \\ ${ }^{1}$ Department of Construction Engineering and Management, Faculty of Civil Engineering, \\ Ho Chi Minh City University of Technology (HCMUT), 268 Ly Thuong Kiet, District 10, Ho Chi Minh, Vietnam \\ ${ }^{2}$ Vietnam National University Ho Chi Minh City, Linh Trung Ward, Thu Duc District, Ho Chi Minh, Vietnam \\ ${ }^{3}$ Department of Project Management, Faculty of Civil Engineering, Ho Chi Minh City Open University, 97 Vo Van Tan Street, \\ District 3, Ho Chi Minh, Vietnam
}

Correspondence should be addressed to Phong Thanh Nguyen; ntphong1711@gmail.com

Received 11 August 2020; Revised 4 November 2020; Accepted 28 November 2020; Published 28 December 2020

Academic Editor: Timothy O. Olawumi

Copyright (C) 2020 Thu Anh Nguyen et al. This is an open access article distributed under the Creative Commons Attribution License, which permits unrestricted use, distribution, and reproduction in any medium, provided the original work is properly cited.

\begin{abstract}
The construction industry has played an essential role in the process of modernization and industrialization and it has also been a major factor in determining the development of the infrastructure for other economic sectors. Construction companies consider the measurement of work progress, which often wastes time and has a low resolution, to be one of the most challenging problems faced by project management. Therefore, this research aimed to propose practical solutions by applying recent technological achievements of the 4.0 industrial revolution to improve the efficiency of the quantity management process. By utilizing the advantages and features of a BIM model and 3D laser scanning, this paper proposes that adopting a BIM model and 3D laser scanning has the potential to improve the accuracy and efficiency of the quantity management process. The case study demonstrated some typical tasks to evaluate accuracy and efficiency as well as to showcase the research proposal.
\end{abstract}

\section{Introduction}

The growth of a national economy leads to growth in the construction industry, which is the backbone of modern industry $[1,2]$. Thus, the sustainable development of the construction industry helps a nation steadily achieve its financial goals. According to the General Statistics Office of Vietnam, statistical test results with $95 \%$ confidence have demonstrated that construction and GDP have a very high correlation of about 97\%; in other words, the two variables GDP and construction tend to have the same pattern from the year 2005 to the year 2017. After steady-state growth, several construction corporations faced challenges and lost momentum in 2018 and 2019. Additionally, other factors such as strong industry competition, pressure from customers, and legal challenges have negatively affected corporate growth rate and the gross profit margin. In the 4.0 revolution, construction activities must ensure quality and reduce time and cost.
Quality control and approval of construction work play a vital role in project management $[3,4]$. Approval of construction is based on quality inspection, measurements, and calculations of all parts of the project, which is built based on the specifications in the contract between the project participants. Progress measurement or the monitoring of work is a mandatory task in a construction project since it validates whether the work has been completed or not. In other words, quantity management is a way to identify project progress. The task of managing the volume of work needs to be done very quickly and accurately to avoid all the time-consuming and mundane activities in a project. Investors guarantee the capital disbursement plan, whereas the contractor has the budgetary authority to carry out and ensure activities during the whole project. As a result, the two parties can execute the contract by recording revenue unfinished or accept volumes that have been carried out to transition to other construction items or to cover up obscured work sections, and so forth. 
Management of approvals faces numerous challenges based on the scale and scope of work and the number of overlapping activities or status (finished or unfinished, the feature of objects). Project managers typically classify construction activities at several levels of detail, quality control, or quantity control. Work approval packages always have a detailed level of a stack or queue (e.g., formwork, reinforcement, concreting, wall, plastering, matit powdering, painting, and finishing). Regarding the current method, there are several limitations in quality control. The first involves worklist statistics. In detail, some tasks must be conducted per technical requirements and actual progress on site, but a surveyor does not take such tasks into account. The second limitation is redundancy or lack of workload, where this error occurs when a quantity surveyor enumerates all the tasks that need to be carried out, but the workload is less or more than the design. Sometimes, the volume schedule has been completed based on the right calculation principle, but the attached measurement unit is wrong, resulting in an unacceptable report. Moreover, unsuitable technology analyzation compared to reality when the chosen method is not followed in the actual construction situation reduces economic efficiency. Current research in Vietnam for the most part analyzes and researches monitoring methods to provide a cost estimation and determine the volume and the cost of construction investment. There is very limited research referring to the determination of the volume of work performed during construction.

Building Information Models (BIMs) are increasingly utilized because they improve the design plan, mitigate conflicts, and minimize risks during a project [5-7]. Although other technologies, such as virtual reality and surveillance with drones, have been commonly used in many countries around the world, they have yet to be used in projects in Vietnam. However, the year 2020 was forecast to be the beginning of a boom in software application in construction project management. The strong competition among construction companies has driven the need to improve productivity and reduce miscalculations and cost. Accordingly, online project management tools and materials management software such as BIM 360 and SiteMAGE have demonstrated their effectiveness in the construction industry.

The method of applying the BIM model to progress measurement has several advantages compared with the common conventional method. Besides automatic calculations and measurement of volume, BIM model can sync information from other software applications such as Microsoft Excel and Microsoft Project. Moreover, if there exists any change in the design during the calculation process, Revit can help to update those changes, with the volume schedule automatically recalculated. Furthermore, Revit can retrieve information codes from norms issued by the Ministry of Construction to estimate and update information. Revit software has very powerful 3D drawing tools and deploys detailed 2D drawings accurately, saves time, and combines with the volume spreadsheet as the basis for BOQ. 3D laser scanning developed as an archeological breakthrough, with fast data collection speed, ultrahigh density in point acquisition, and data acquisition with high accuracy. Thanks to this invention, all tasks relevant to monitoring work have become faster, easier, and more accurate.

The purpose of this research is to design a practical solution applying BIM integrated with laser scanning to improve the efficiency of the quantity management process. This study assesses the current situation and identifies existing problems in the quantity managing process in the Vietnam construction industry. By utilizing the advantages and features of the BIM model integrated with 3D laser technology to the quantity management procedure, a general procedure for implementation is proposed, aiming to support and improve accuracy and efficiency. This proposed procedure can then be applied to several typical tasks of a real project. When the procedure is conducted and applied, this research will evaluate and compare between the conventional method and the BIM-laser scanning method for accuracy and efficiency.

\section{Research Background}

Imprecise methods of quantity management are ordinarily based on the actual work that was executed at the field project, using construction drawings or the as-built drawings as a premise for calculation. Generally, engineers use software that supports Microsoft Excel or an estimation computer program modified based on Microsoft Excel to manage and calculate volume (e.g., the volume of soil for earthmoving, the volume of materials, concrete, etc.). The above methods have the advantage of being simple to implement and adapt [8]. However, this approach makes it challenging to upgrade information during the implementation process and to determine the accuracy of the implementation volume, especially for large and complex projects and projects under urgent timelines $[9,10]$.

To enhance accuracy in determining construction volume and construction investment costs, Vietnam's Ministry of Construction declared Decision No. 451/QD-BXD on May 25, 2017. The effectiveness of the above guidelines was dependent on the information being strongly considered, researched, and evaluated. Thus, it was vital to find new solutions to improve the resolution in the estimation of mass removal. The goal has been to improve the accuracy and reliability of investment and budget decisions. Additionally, errors in volume estimation required the development of various solutions to overcome and constrain these mistakes. Such proposals include promulgating normative documents, focusing on material take-off orders, improving the quality of design documents, and applying the expertise of individuals to perform and enhance cross-checking [11, 12]. Conversely, these proposals are still only theoretical solutions. No specific procedures or strategies were suggested for carrying out these proposals.

This illustrates that BIM is considered as not particularly new, but as something interesting, and was only recently applied in Vietnam. In essence, BIM, as a design document, consists of digital files or data $[13,14]$. BIM's progress is supported by various tools, technologies, and contracts 
involving the generation and administration of digital representations of physical and functional characteristics of places containing close relationships with each other in terms of space, size, quantity, and material of each structure. All the information is exchanged and associated online together through software to support progress measurements, project management, and project control. By combining data about the parts of the building with other information such as norms, financial budget, and construction progress, a virtual reality model of the building is generated to optimize design, construction, and operation management.

Innovations such as BIM, virtual design, virtual construction, and 3D laser scanning are continuously changing the concept of building construction in a digital era. Among the changes, the emergence of 3D laser scanning has become the most well known. 3D laser scanning is a technology that uses a laser beam to capture the features of objects in multiple directions within and around a structure $[15,16]$. Once the data points have been captured (they are aggregated into a "point cloud" and assigned $X, Y$, and $Z$ coordinates), they are saved digitally to describe spatial relationships between objects, as these point clouds provide a full characteristic depiction of the receiving entities [17]. The resolution or the distance $(\mathrm{mm})$ between points in the point depends on the object's location relative to the scanner and the resolution angle [18]. Depending on the device, the shape of the object, as well as the distance to the object, can be obtained as point cloud data precise to less than $2 \mathrm{~mm}$ and the speed of recording data up to millions of points per second. Laser scanning was originally pursued to speed the collection of spatial data and improve its resolution.

A 3D laser scanner works by rotating a laser beam at a high speed that then reflects from a surface and measures the reflected pulses by sensors [19]. The laser automatically rotates around its vertical axis in a horizontal plane, and, in a vertical plane, a reflective mirror reflects the laser beam up and down. When the laser touches an object's surface, the device will automatically note the position based on the reflection time of the laser. From this, the device can easily calculate the distance to the object. Data on the horizontal angle of the laser and the corresponding vertical angle of the rotating mirror are also recorded. 3D laser scanning technology has a noticeably fast data collection speed, highly accurate spatial data, and a minimum of unwanted data. This speeds up postprocessing significantly, making it a hasslefree process. Once the point cloud has been created in a 3D spatial form, the data can be exported into software such as AutoCAD or Revit to construct complex geometric BIM models. Using a BIM model, a user can export an exact volume schedule through the application of 3D laser scanning technology to approve the volume at each point of various construction phases or stages and to accurately determine the amount of work done. Hence, a new schedule, as well as the volume of required material for the remaining tasks, can be planned.

In the traditional method, the assessment of surface flatness was done manually with a ruler or with an altimeter, which is very time-consuming and can take only individual measurements. In contrast, laser scanners can quickly perform several measurement formulations. The laser data obtained is essential to verify the accuracy and quality of building models [20]. To assess the quality and effectiveness of current information models and 3D laser scanning data, a method of deviation analysis was developed by Tang et al. [21]. This analysis was used to overcome the limitations of physical measurement methods on the quality of data collected by the laser and BIM model. It was proved that this method could detect forecast quality problems and address all the requirements for quality, details, and data collection and for a BIM model.

There is a more persuasive argument that using laser scanning to evaluate the accuracy of the BIM model is less time-consuming and accurate than traditional manual processes. It is undeniable that this technology digitizes a considerable amount of information that can be useful for future applications, and it also provides a temporary solution to the current problems in the construction industry [22]. Research has shown that there are many uses for laser scanning for all phases of a project, and there is a potential benefit of integrating accurate data with the BIM model. Randall [23] formulated construction engineering requirements to integrate laser scanning technology and the BIM model. This combination offers a greater advantage than conventional methods to facilitate the design and construction of complete and accurate conditions from laser scanning data.

To some extent, the framework was developed to appraise the dimensions and surface quality of prefabricated concrete components using BIM and 3D laser scanning $[24,25]$. Once the framework is completed, the engineer can determine the tolerance of a component and classify the information and details of the elements through the BIM library so that on-site engineers can access and check the status of the assigned precast concrete structure [24]. Laser scanning is an effective means to determine the current status of a building before construction, allowing contractors to discover design issues in the construction process and improve the cost reduction capabilities of the construction $[24,25]$. BIM also has many other advantages and is an effective tool to solve the problem of measuring volume for construction work.

Computer vision technology to assist a project manager in making a masterplan, arranging human resources, controlling time, and managing cost was explored ten years ago by Zang et al. [26] and Samir [27, 28]. Twenty-six case studies of 3D and 4D models were conducted to show how $3 \mathrm{D}$ and $4 \mathrm{D}$ models were applied to address project challenges [29]. A framework created from the survey illustrated that the construction industry could benefit from $3 \mathrm{D}$ and $4 \mathrm{D}$ models, which are managed with BIM and laser scanning, for virtual review of facility designs during the design phase of the project and for virtual analysis of construction sequencing during the construction phase. Thus, it is important to develop a deep understanding of how analyzing laser data plays an essential role in the future of AEC [30].

BIM and 3D laser scanning are crucial from the perspective of construction project management staff at 
construction sites. Cost improvements, ease of communication, reduced omission, and order changes are examples of the benefits of using BIM. 3D laser scanning is beneficial in showing the 3D models of the project, compared with plan data and information sharing among stakeholders [31]. However, some shortcomings of these technologies are their high cost, training requirements, and large data size. Overall, these technologies help improve work efficiency and have the potential to solve existing problems.

\section{Research Methodology}

The research methodology is illustrated in Figure 1. The flowchart includes seven main steps: initiation, the determination of the research problem through the interview section, experiments, and evaluation to conclusion and recommendation. This research emphasizes workflow for applying BIM and 3D laser scanning in quantity management through questionnaires, surveys, manipulating preexisting statistical data using computational techniques, and emulating the proposed process in a real project for comparison and evaluation.

First, an overview of research about quantity management was extracted to clarify issues in a range of topics and to conduct a rapid review. Based on a data survey collected from experts performing work as quantity surveyors, the study identified the problem and research aims. The survey participants received a questionnaire and participated in interviews to supply information from their experiences about the current status of contemporary methods. After the interviews, feasibility verification was done for BIM and 3D laser scan per the research issues. At this step, the authors collected appropriate domestic and international materials related to BIM applications and 3D laser scanning technology to identify the advantages and drawbacks of BIM and 3D laser scanning applications in quantity management in the construction industry. Next, the conceptual process, after being proposed, was applied to an actual project to evaluate its effectiveness. At the proposal step, software to process point cloud data included the following: Leica Cyclone Register 360, BuildIT Construction, FARO Scene, and FARO As-Built Autodesk Revit. Software to create a BIM model included AutoCAD 3D and Revit. A comparison sheet was created to compare the volume obtained from the proposed research procedure versus conventional implementation methods and to clarify the pros and cons of the proposed process. The participants in the interviews for process evaluation are experts and engineers working as quantity surveyors responsible for the bill of quantity, a schedule reporting all building elements volume and cost. Lastly, the study concludes with conclusions and recommendations for future studies.

The survey on the volume of work, appropriate with the construction phase, is a relatively broad scope of work. Limitations in the researchers' ability, expenditure, and limited time contributed to choosing sample surveying instead of population surveying. This study used a nonrandom sampling method and utilized a one-way technique combined with a two-way technique for data collection. Face-to-

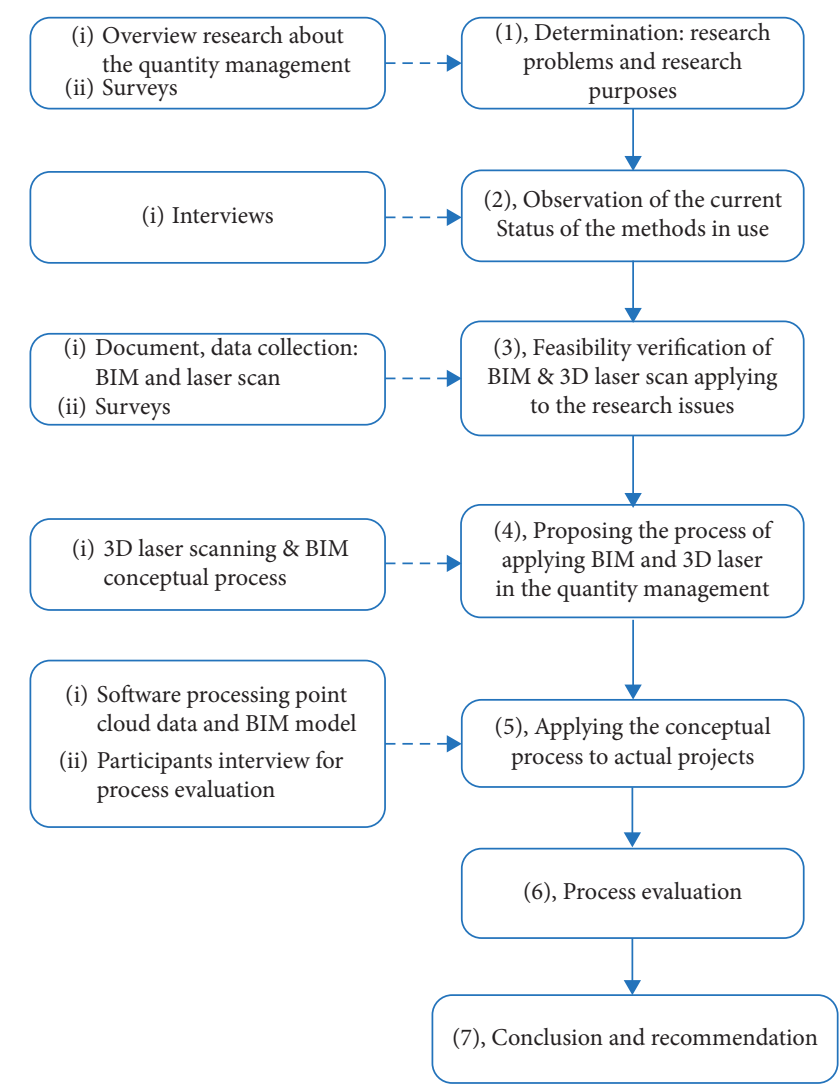

Figure 1: Research process.

face interviews were set up and 50 questionnaires were sent to 200 experts currently working as quantity surveyors, project managers in construction units, supervision consultants, and owners in Ho Chi Minh City, Vietnam. Several complex questions were asked directly through face-to-face interviews. The interviews and questionnaires were designed to determine the appropriate volume monitoring method as well as the pros and cons of such methods and then sum up the current problems of current methods and evaluate the implementation process. The questionnaire included content related to the research objectives and was in the form of multiple-choice questions using a 5-level Likert scale (see Appendix A in Supplementary Materials). A descriptive statistical analysis method was used to analyze the data obtained from the multiple-choice and Likert-scale questions. In the Likert survey, each option was averaged on the Likert scale and then ranked in descending order of the average values of the options to determine the level of choice. Multiple-choice questions allow calculation of the percentage of options based on the total collected number of surveys. With that data, surveyor rank and generalized options were listed in descending order. The purpose of the analysis was to find the most frequently chosen options.

From the statistical results, we proposed the process of applying BIM and 3D laser scanning for quantity management. Again, a survey-interview was conducted (see Appendix B in Supplementary Materials). The application processes are presented in the form of flowcharts with the general contents of the steps to create a guide for companies 
that want to apply BIM and 3D laser scanning for volume monitoring. The proposed process is not explored deeply in detail but just notes the necessary overall steps. This concept is then implemented for real projects to evaluate the optimism of the conceptual process. The criteria for evaluation include optimism and feasibility in QS, BIM, and 3D laser scanning.

The survey results showed that the most frequent benefits of BIM were the improvement and accurate analysis of the construction site (more than $62 \%$ in votes). More than half of survey participants believed that BIM improved team coordination, operations, and maintenance and reduced order changes, which was the second-most frequently noted benefit. Creating a 3D model was the most cited benefit (56\%) when using laser scanning. Respondents' views regarding 3D laser scanning deficiencies included $68 \%$ of respondents that indicated the high cost of equipment purchase, $36 \%$ for large file size, $29 \%$ for high maintenance costs, $21 \%$ for low-quality output, and $29 \%$ for uncertainty. Additionally, a high uncertainty response rate $(29 \%-30 \%$ of participants) indicates a lower level of understanding of 3D laser scanning compared to BIM among construction engineers.

\section{Results and Discussion}

Based on the survey data and expert interviews and research documents, domestic and international documents related to BIM model applications, and 3D laser scanning technology, the BIM-3D laser application process was applied to volume management. The process is illustrated in Figure 2. This proposed operation was applied for a sports stadium located in Go Vap district, Vietnam, which was a five-story building with one basement. When conducting the research, the project was in progress at the super-structure construction stage and wall finishing stage. With limited time, as well as minimal 3D laser scanning equipment, the research was not able to fully apply the proposed process for the project but could only implement the process with the following limitations: implementation of the process application on a particular area of the project with collection of data for some construction work such as wall construction, column concreting, lintel concreting, and pillar concreting.

The overall operation is a seven-stage process (Figure 2). Looking at the diagram more closely, the process begins when the $3 \mathrm{D}$ laser scanning equipment is set up and settings such as resolution, distance to object, and scanner speed are adjusted to determine the location of the machine. While evaluating the status of the ground plan and the technical characteristics of the hardware, the machine is appropriately placed and arranged at the project where all data can be collected. A construction site offers some of the worst instances of cluttered scenes. Additionally, there are changes to the true structure over time, and, as such, actual operation may include a large number of extra spurious events. These can broadly be classified as noise and

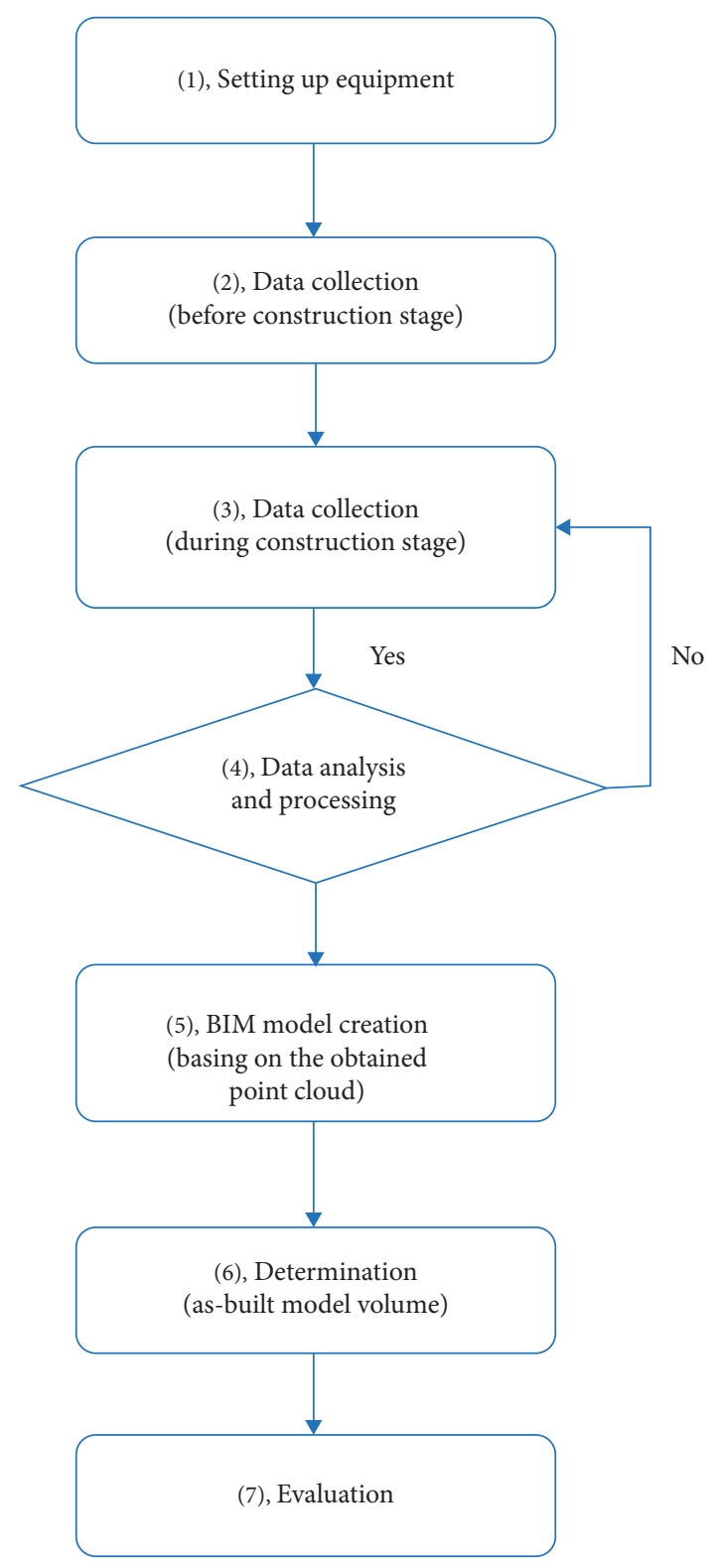

FIGURE 2: BIM-3D laser scanning process.

incorporate impacts that are environmental (light and shadow, rain, snow, etc.), partial (longer cumulative stages of work such as pouring concrete), and incidental (people and equipment moving or remaining still for some time) [26]. These factors sharply affect the accuracy of the obtained data. Subsequently, a careful review of these conditions must be made before determining the location of the machine.

The second step is data collection before the construction site. In this step, the user has to mark the entire ground plane and then locate a fixed mark or target board according to the coordinate frame of the project to ensure that all necessary data are obtained. For complex projects, where the building components have a considerable amount of details, the determination of stations in the project or set of target 
boards helps make point cloud data acquisition faster and more exact. In the case of a component that is being built between other existing buildings, the entire collection of data on surrounding areas will help collect data and capture it several times at different locations to affirm the field conditions.

In step three, data is collected at the construction site. Engineers should locate 3D laser scanning devices in every room and floor of the interior and exterior of the project, especially in regions that have numerous hidden corners, interference from people passing through, or fixed obstacles. Subsequently, data collection must be gathered continuously to gain detailed point cloud 3D data, especially at the surface of the top-finishing work. The point cloud data then is processed and analyzed by specialized software, such as Faro Scene or Leica Cyclone Register 360. The collected data is matched and merged by a station target board or automatic match; then, the noise is removed.

Proceeding to the next stage, from the obtained point cloud, a model is created by exporting data and importing point cloud data into relevant software such as Revit and Navisworks. The engineer creates an as-built model based on the orthogonal distance of points on the object surface of the point cloud and the similarity in the direction of the local standard faces around the point cloud. After importing data into the software, building objects on the BIM model are set up following the project's components based on point cloud data and the images obtained. The last part of this step is to align the objects of the BIM model with the point cloud, so each object of the BIM model is matched with the points of the point cloud.

The created information model in step five can be used to determine volume or export workloads in step six. The final step, evaluation, based on the results of the volumes obtained in steps allows for a comparison and evaluation against conventional methods. After creating the process, the research proceeds to apply the proposed process to the actual work to evaluate the process. When the data collection process of the project has been completed, exported, and processed to the point cloud data obtained by Leica Cyclone Register 360 software, the data pairing at the machine station is performed, and the noise point deletes all unwanted data from the model (i.e., the triangle represents the machine placement), as shown in Figures 3 and 4.

To import point cloud data into the Revit software to build models, (i) check the point cloud model on the ground plan and the cross section view; (ii) compare with actual image taken from the 3D laser scanning device to determine the dimensions of structures, such as width, height, and an actual shape obtained (see Figure 5).

Two volume schedules were exported based on two methods: conventional method (using a tape measure, tape measure combined with a laser distance meter, etc.) and BIM-3D laser scanning method. In the conventional method, the building was broken down and divided by zones to calculate the volume of building components. The volume schedules were sorted by floor and apartment units and types of structures for BOQ. Microsoft Excel then managed the obtained data. The contractor, supervision consultant, or owner would check and evaluate the completed volume of each apartment or area weekly and update the status into the prepared Excel file. As mentioned, the calculation and determination of volume by traditional methods were still quite manual, highly dependent on the skills, capacity, and sensory perception of the manager, and it took time to determine the exact volume of execution. In BIM-3D laser scanning, the volume schedule of masonry walls, precast concrete, and pillars were executed directly and automatically from the built BIM model. Based on the obtained volume, a comparison and evaluation between the two strategies are illustrated in Table 1.

There is a belief that BIM operation is only applicable for a new building in which design drawings are available for $3 \mathrm{D}$ modeling by BIM tools, but this is not true. BIM operation also can be used for existing buildings or during constructing, and laser scanning obtains point cloud data with precise length $\mathrm{x}$ width $\mathrm{x}$ height parameters that the BIM can model. Without the contribution of the laser scanning equipment, BIM cannot access the current status of the construction site due to the fact that BIM tools create a $3 \mathrm{D}$ model only when having exact parameters of that object. Although surveyors can export a detailed BOQ report with the support of BIM operation in the tender stage, with the support of 3D laser scanning, they even can determine the exact volume or status of work in the acceptance of construction work or provide a status on a particular construction phase. The bar chart below illustrates the results of the second survey of 21 individuals with more than seven years of experience in quantity management and project management who perform quantity management by traditional methods to assess the level of feasibility when applying the process in implementing a real project (see Figure 6).

Concerning the efficiency of applying BIM-3D laser scanning projects, four individuals said that they could not give any evaluation and that they needed more time for this decision. They are neophytes in this new integration. 3D laser scanning is still entirely new, such that there are reservations about precision when projects have too many overlapping tasks that are not easily handled. Eight individuals evaluated that the process of applying BIM and $3 \mathrm{D}$ laser scanning to the implementation of volume management was effective but needed consideration on how to apply it on ongoing project Due to doubts about the feasibility of managing the volume of items, future research can look at finishing work, such as through an MEP system. It is interesting to note that approximately half of the participants (9 people) evaluated the process of applying BIM and 3D laser scanning as an effective implementation of quantity management that has potential and wanted to apply it to real projects. However, there are still doubts about the high cost of investment in equipment as well as limited human resources to operate the technology.

Because of the limitation of time, budget, and equipment throughout the surveying process, this study only applied the process to a part of the project. For reasons of information security, the study only contacted a limited number of quantity surveyors and project managers; thus there was 


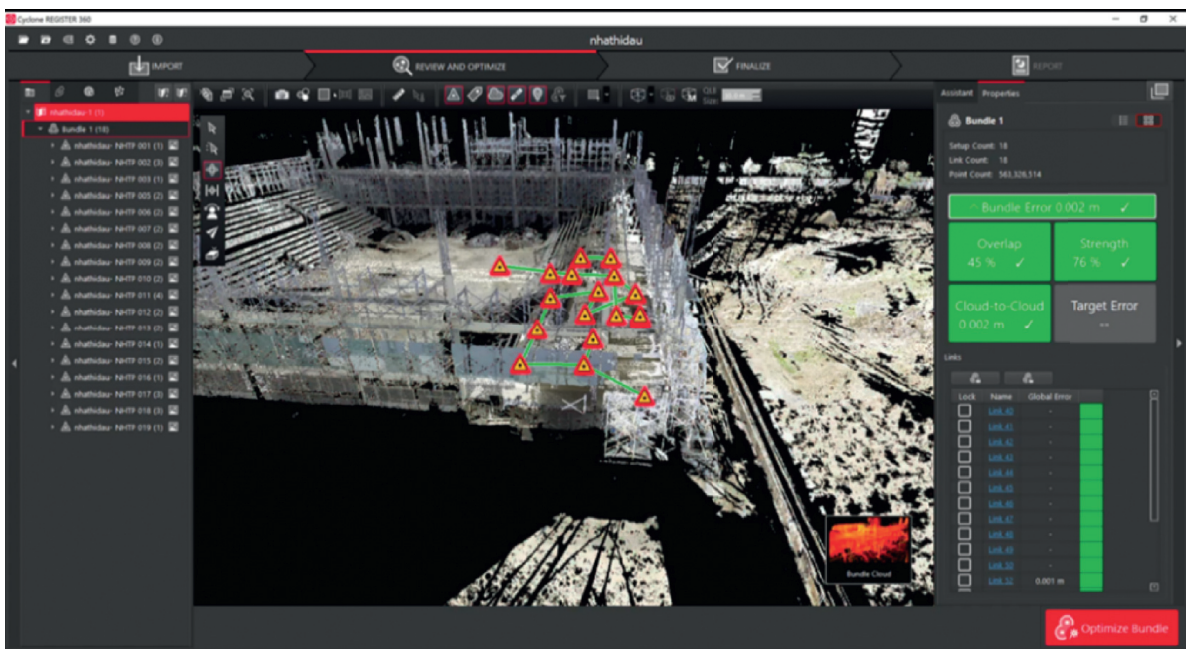

Figure 3: Data processing in Leica Cyclone Register 360 software environment.

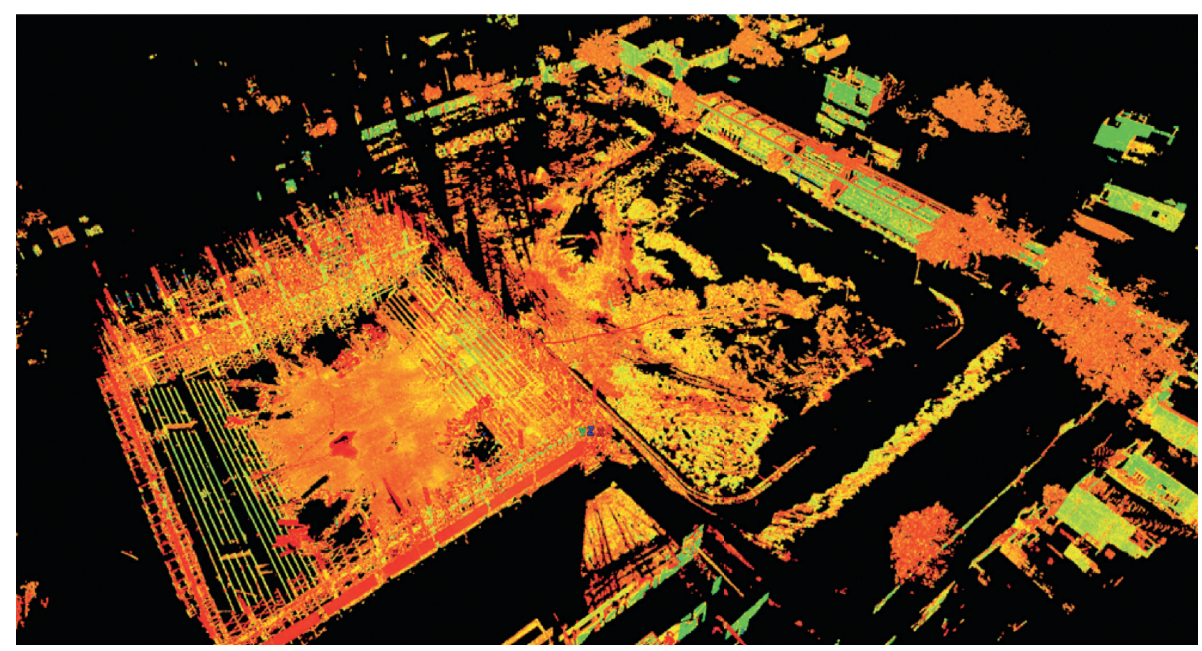

FIgURE 4: The collected point cloud.

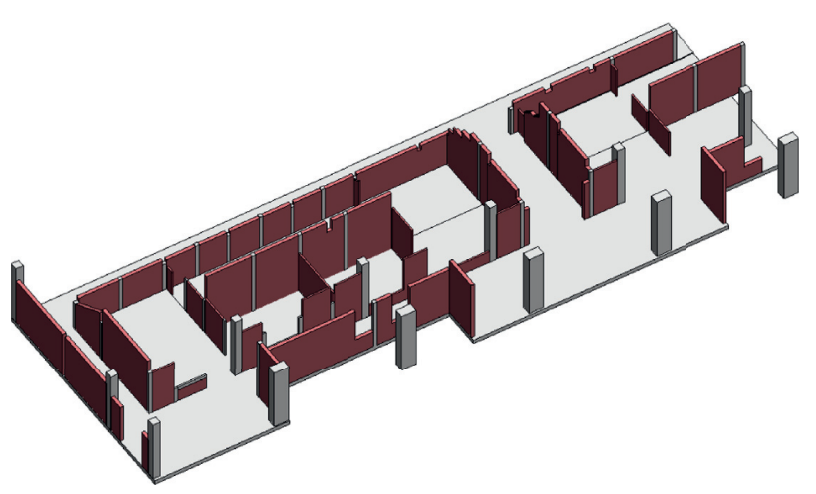

FIGURE 5: The BIM model created from the obtained point cloud by Revit software.

insufficient information data to cover the entire survey sample. 3D laser scanning technology is still relatively new in Vietnam, so Vietnamese civil engineers still do not have much experience with this technology. In subsequent studies, other data collection methods should be applied to a full sample. Determining the implementation volume of a project based on a BIM model and 3D laser scanning technology appears to be theoretically feasible and is still relatively simple. These procedures need to be developed at a more detailed survey level to assess accuracy and feasibility when applied to an actual project. Simultaneously, point cloud data collected during 3D laser scanning needs to be applied to more applications in construction and project management.

The results of the study show the usability and potential of the application of BIM and 3D laser scanning technology in quantity management and project management. However, due to the limited time and equipment for conducting the research, the research was only conducted for general processes. Based on the survey results, the research has explored in part the problems encountered in volume monitoring in a construction project and demonstrated the effectiveness of BIM application and 3D laser scanning technology compared with current conventional methods. The study contributed more documentation on the integration between BIM and 3D laser scanning technology in 
TABLE 1: Evaluation and comparison between the conventional method and BIM-3D laser scanning method.

\begin{tabular}{|c|c|c|c|}
\hline No. & Content & Conventional method & BIM-3D laser scanning \\
\hline 1 & $\begin{array}{l}\text { Data collection time- } \\
\text { point cloud data } \\
\text { processing time }\end{array}$ & $\begin{array}{l}\text { The manual measuring process is time-consuming } \\
\text { and error-prone. The lack of accurate and up-to- } \\
\text { date as-built information often occurs because of } \\
\text { limitations in working time and budget for manual } \\
\text { data collection. Only considering the time to } \\
\text { calculate the exact volume of masonry walls, lintels, } \\
\text { or correct pillars. The time required includes (i) at } \\
\text { least } 1 \text { day to measure current volumes and (ii) } \\
\text { approximately } 3-4 \text { hours to input and calculate the } \\
\text { volume. Furthermore, some of the unfinished } \\
\text { construction works have indeterminate shapes, } \\
\text { which makes it necessary to make a determination } \\
\text { of the execution volume, which consumes more } \\
\text { time. }\end{array}$ & $\begin{array}{l}\text { All efforts of the 3D laser scanning are concerned } \\
\text { with building model reconstruction and not with just } \\
\text { measuring progress; the laser reflection collects all } \\
\text { spatial data. For a project with many completed items } \\
\text { at the same time, such as ceiling construction, wall } \\
\text { painting, and tiling, it is possible to distinguish and } \\
\text { calculate the entire workload of the project with the } \\
\text { laser scan and BIM. In the testing project for this } \\
\text { research, the authors set up } 18 \text { stations; the total } \\
\text { implementation time was about } 1 \text { hour and } 30 \\
\text { minutes, including the time to place the machine at } \\
\text { various locations to collect data. In the point cloud } \\
\text { data processing phase, it took } 1 \text { hour and } 30 \text { minutes } \\
\text { to import and merge data and remove unnecessary } \\
\text { point cloud data. The total time to build a BIM model } \\
\text { from point cloud data and export the volumes was } \\
\text { about } 4 \text { hours. If a projector needs to calculate the } \\
\text { volume of a ceiling or tile, it only takes about } 1-2 \\
\text { more hours to build the model from the point cloud } \\
\text { model. The entire application process took nearly } 8 \\
\text { hours (equivalent to about one working day) to } \\
\text { produce the actual BIM model and export a detailed } \\
\text { volume schedule. }\end{array}$ \\
\hline
\end{tabular}

In this research, the testing project has a relatively simple shape of walls or concrete elements.

$2 \quad$ Accuracy

However, the volume calculated that agrees with the Laser scanning technology implies that the collected conventional method is lower, approximately $7.16 \%$ results can be very accurate with a high level of detail. (for masonry walls) and around 1.93\% (for lintel) The BIM model is built with nearly $99 \%$ precision. compared to the volume exported from the BIM-3D laser scanning model.

\begin{tabular}{|c|c|c|c|}
\hline 3 & Cost & $\begin{array}{l}\text { Volume determination mistakes can result in } \\
\text { project delays, expenses for consultants, and } \\
\text { handicapping the managers' ability to monitor } \\
\text { schedule, cost, and other performance indicators. } \\
\text { Based only on the temporary price for a consultant, } \\
\text { counting on the wall volume, there is a } 7.16 \% \\
\text { increase in the cost of wall construction tasks } \\
\text { compared to the BIM-laser scanning method. This } \\
\text { difference originated from volume determination } \\
\text { mistakes caused by the conventional method. }\end{array}$ & $\begin{array}{l}\text { The cost for BIM and 3D laser scanning } \\
\text { implementation is relatively high ( } 70.000 \text { USD for } \\
\text { RTC360). Not only is the investment in equipment } \\
\text { and software expensive, but also it requires a high } \\
\text { level of skill. However, implementation takes less } \\
\text { time and manpower, and the resulting model can be } \\
\text { used throughout the life of the project (such as } \\
\text { updating the actual conditions of the project } \\
\text { compared to the design condition, making accurate } \\
\text { as-built drawings, providing documents for } \\
\text { operation, and maintenance of the project). As a } \\
\text { result, the overall costs become more reasonable. }\end{array}$ \\
\hline
\end{tabular}

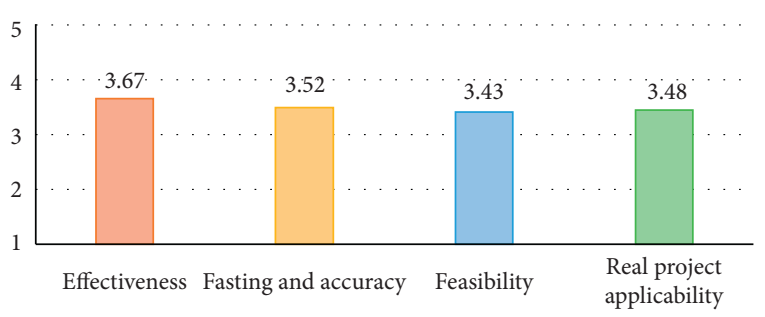

Figure 6: Evaluation of BIM-3D laser scanning compared to the conventional method.

the construction industry. Several vital factors were identified, which affect the application of BIM and 3D laser scanning technology, helping companies to take significant preparation steps and anticipate difficulties before adoption.

\section{Conclusions}

Ultimately, the integration of BIM-laser scanning to quantity surveying provided an improved method. With laser scanning, building owners can have a comprehensive product throughout the building life cycle without the expensive cost of a full BIM model. Better still, on the off chance that a full BIM model is later necessary, the point cloud data collected by laser scanners can be utilized, eliminating any demands for a new survey and subsequently saving time and cost. Indeed, determining the volume of work carried out in construction projects by traditional methods is difficult, and accuracy and reliability typically are not high. The evaluation requires a lengthy period of time and often results in a controversy between the project's participants. Meanwhile, the project still has many tasks that 
need to be done to quickly and accurately determine the implementation volume before deploying the next project. Manually determining the volume depends heavily on the management capacity of the individuals participating in the project.

The implementation of BIM and 3D laser scanning can resolve all the above limitations of the conventional methods. Using laser scanning, the status of the site can be transferred to digital modules that are then processed to create spatial objects, monitor the volume of work, export and prepare the BOQ schedule, and create the BIM model for the later O\&M phase. The method requires less time and labor, and the obtained model (point cloud model, BIM model) can be used throughout the building's life cycle. The main problematic limitation of these technologies is the initial investment cost for laser scanners and training fees. However, this can be solved when more subconsultants are working in this field. Although the process of implementing the application of BIM and 3D laser scanning to a real project has just spread out at a relatively small scale in project construction work, the results show the potential of applying a BIM model and 3D laser scanning technology to quantity management and project management. With one engineer and one laser scanner, a surveyor can quickly complete an evaluation in three steps: installation of the laser scanner on site, scanning the construction components before and during the construction phase, and analyzing and processing point cloud data to create a BIM model based on the obtained point cloud to determine the volume of works for project requirements.

There were some limitations in this research. Due to time and equipment limitations, the research could only be accomplished at the level of general processes and applications for some basic construction tasks. Thus, future studies need to clarify and detail different construction categories, while making this technology application process a complete platform to manage and connect all stages throughout the project life cycle. The research contributed additional information on the integration between BIM and 3D laser scanning technology to the construction industry. Moreover, identifying important factors affecting the application of the BIM model and the 3D laser scanning technology can help businesses take practical steps to use them and anticipate difficulties before applying these technologies.

\section{Data Availability}

The data used to support the findings of this study are available from the corresponding author upon request.

\section{Conflicts of Interest}

The authors declare that they have no conflicts of interest.

\section{Acknowledgments}

This research is funded by Vietnam National University, Ho Chi Minh City (VNU-HCM) under grant number C201920-42. We would like to thank Ho Chi Minh City University of Technology (HCMUT), VNU-HCM for the support of time and facilities for this study. The authors also thank Pham Truong An, Nguyen Manh Cuong, Phuong Thanh Phan and Khoa Dang Vo, Ph.D. Candidate, for their help in this research.

\section{Supplementary Materials}

Appendix A: the questionnaire included content related to the research objectives and was in the form of multiplechoice questions using a 5-level Likert scale. Appendix B: the process of applying BIM and 3D laser for quantity management. Again, a survey-interview was conducted. (Supplementary Materials)

\section{References}

[1] D.-L. Luong, D.-H. Tran, and P. T. Nguyen, "Optimizing multi-mode time-cost-quality trade-off of construction project using opposition multiple objective difference evolution," International Journal of Construction Management, vol. 18, pp. 1-13, 2018.

[2] P. T. Nguyen, V. N. Nguyen, L. H. Pham, T. A. Nguyen, Q. L. H. T. T. Nguyen, and V. D. B. Huynh, "Application of supply chain management in construction industry," Advances in Science and Technology Research Journal, vol. 12, 2018.

[3] P. T. Nguyen, T. A. Nguyen, Q. Nguyen, and V. Huynh, "Application of SWOT for construction company quality management using building information modeling," Journal of Mechanics of Continua and Mathematical Sciences, vol. 13, no. 5, pp. 25-33, 2018.

[4] P. T. Nguyen, "Construction project quality management using building information modeling 360 fields," International Journal of Advanced Computer Science and Applications, vol. 9, no. 10, pp. 228-233, 2018.

[5] Z.-Z. Hu, P.-L. Tian, S.-W. Li, and J.-P. Zhang, "BIM-based integrated delivery technologies for intelligent MEP management in the operation and maintenance phase," Advances in Engineering Software, vol. 115, pp. 1-16, 2018.

[6] Y.-W. Zhou, Z.-Z. Hu, J.-R. Lin, and J.-P. Zhang, "A review on 3D spatial data analytics for building information models," Archives of Computational Methods in Engineering, vol. 27, no. 2, pp. 1-15, 2019.

[7] P. Li, S. Zheng, H. Si, and K. Xu, "Critical challenges for BIM adoption in small and medium-sized enterprises: evidence from China," Advances in Civil Engineering, vol. 2019, Article ID 9482350, 2019.

[8] C. Harrison and D. Thurnell, 5D BIM in a Consulting Quantity Surveying Environment, 2014.

[9] T. Akanbi, J. Zhang, and Y.-C. Lee, "Automated item matching and pricing (IMP) for wood building elements to support BIM-based wood construction cost estimation," in Proceedings of the Computing in Civil Engineering 2019: Visualization, Information Modeling, and Simulation: American Society of Civil Engineers Reston, pp. 402-409, Reston, VA, USA, June 2019.

[10] J. J. Hannon, "Estimators' functional role change with BIM," AACE International Transactions, vol. 2007, p. IT31, 2007.

[11] L. Sabol, "Challenges in cost estimating with building information modeling," in Proceedings of the IFMA World Workplace, pp. 1-16, Dallas, TX, USA, April 2008. 
[12] W. M. Matipa, P. Cunnigham, and B. Naik, "Assessing the impact of new rules of cost planning on BIM schema pertinent to quantity surveying practice," Proceedings 26th Annual ARCOM Conference, vol. 1, pp. 625-632, 2010.

[13] J. Wu and J. Zhang, "New automated BIM object classification method to support BIM interoperability," Journal of Computing in Civil Engineering, vol. 33, no. 5, Article ID 04019033, 2019.

[14] J. Wu and J. Zhang, "Introducing geometric signatures of architecture, engineering, and construction objects and a new BIM dataset," in Proceedings of the Computing in Civil Engineering 2019: Visualization, Information Modeling, and Simulation: American Society of Civil Engineers Reston, pp. 264-271, Reston, VA, USA, June 2019.

[15] J. Guo, Q. Wang, and J.-H. Park, "Geometric quality inspection of prefabricated MEP modules with 3D laser scanning," Automation in Construction, vol. 111, p. 103053, 2020.

[16] J. Guo and Q. Wang, "Dimensional quality inspection of prefabricated MEP modules with 3D laser scanning," in Proceedings of the Computing in Civil Engineering 2019: Data, Sensing, and Analytics: American Society of Civil Engineers Reston, VA, pp. 171-177, Reston, VA, USA, June 2019.

[17] Q. Wang, Y. Tan, and Z. Mei, "Computational methods of acquisition and processing of $3 \mathrm{D}$ point cloud data for construction applications," Archives of Computational Methods in Engineering, vol. 27, no. 2, pp. 479-499, 2020.

[18] S. El-Omari and O. Moselhi, "Integrating 3D laser scanning and photogrammetry for progress measurement of construction work," Automation in Construction, vol. 18, no. 1, pp. 1-9, 2008.

[19] F. Rodrigues, J. Teixeira, R. Matos, and H. Rodrigues, "Development of a web application for historical building management through BIM technology," Advances in Civil Engineering, vol. 2019, 2019.

[20] D. Huber, B. Akinci, P. Tang, A. Adan, B. Okorn, and X. Xiong, "Using laser scanners for modeling and analysis in architecture, engineering, and construction," in Proceedings of the 2010 44th Annual Conference on Information Sciences and Systems (CISS), pp. 1-6, IEEE, Princeton, NJ, USA, March 2010.

[21] P. Tang, E. B. Anil, B. Akinci, and D. Huber, "Efficient and effective quality assessment of as-is building information models and 3D laser-scanned data," Computing in Civil Engineering, vol. 2011, pp. 486-493, 2011.

[22] B. Giel and R. Issa, "Using laser scanning to access the accuracy of as-built BIM," Computing in Civil Engineering, vol. 2011, pp. 665-672, 2011.

[23] T. Randall, "Construction engineering requirements for integrating laser scanning technology and building information modeling," Journal of Construction Engineering and Management, vol. 137, no. 10, pp. 797-805, 2011.

[24] M.-K. Kim, J. C. P. Cheng, H. Sohn, and C.-C. Chang, "A framework for dimensional and surface quality assessment of precast concrete elements using BIM and 3D laser scanning," Automation in Construction, vol. 49, pp. 225-238, 2015.

[25] A. Jrade and J. Lessard, "An integrated BIM system to track the time and cost of construction projects: a case study," Journal of Construction Engineering, vol. 2015, 2015.

[26] X. Zhang, N. Bakis, T. C. Lukins et al., "Automating progress measurement of construction projects," Automation in Construction, vol. 18, no. 3, pp. 294-301, 2009.

[27] S. El-Omari and O. Moselhi, "Integrating automated data acquisition technologies for progress reporting of construction projects," Automation in Construction, vol. 20, no. 6, pp. 699-705, 2011.

[28] T. Hartmann, J. Gao, and M. Fischer, "Areas of application for 3D and 4D models on construction projects," Journal of Construction Engineering and Management, vol. 134, no. 10, pp. 776-785, 2008.

[29] H. Daniel, "Using laser scanners for modeling and analysis in architecture, engineering, and construction," in Proceedings of the 44th Annual Conference on Information Sciences and Systems, pp. 1-6, (CISS), Princeton, NJ, USA, March 2010.

[30] P. Tang, "Efficient and effective quality assessment of as-is building information models and 3D laser-scanned data," Computing in Civil Engineering, vol. 2011, pp. 486-493, 2011.

[31] K. Alomari, J. Gambatese, and M. J. Olsen, "Role of BIM and 3D laser scanning on job sites from the perspective of construction project management personnel," in Proceedings of the Construction Research Congress, 2016, pp. 2532-2541, San Juan, Puerto Rico, May 2016. 